\section{TENDÊNCIA DA HANSENÍASE EM MENORES DE 15 ANOS POR REGIÃO DO BRASIL ENTRE 2007 A 2017}

\section{TENDENCY OF HANSENIASIS IN MINORS UNDER 15 YEARS OLD BY REGION OF BRAZIL BETWEEN 2007 TO 2017}

Ana Karla Araújo Nascimento Costa ${ }^{1}$ / Álisson Neves Santos ${ }^{1} /$ Kelle Araújo Nascimento Alves ${ }^{1, *}$

\section{INTRODUÇÃO}

A hanseníase é uma doença infecciosa crônica causada pelo parasita Mycobacterium leprae que, possui como atração primordial as células do sistema nervoso periférico e as células da pele. Umas das características principais do bacilo é a capacidade de resistência ao álcool ácido, no qual faz com que o mesmo seja corado pelo método de Ziehl Neelsen, apresentando-se como Gram positivo (MONTALVÃO et al., 2018).

Se tratando da transmissão da doença, a própria se dá majoritariamente através das vias aéreas superiores, onde o bacilo após infecção direciona-se às células de Schwann, células essas no qual o parasita possui uma maior afinidade. Já no que se refere às condições clínicas do indivíduo a mesma é condizente de acordo com a capacidade de defesa do sistema imunológico da pessoa contra o $\mathrm{M}$. leprae (MARQUES et al., 2017).

O tempo de incubação da hanseníase varia em torno de 5 a 10 anos, sendo este considerado um tempo longo de incubação, tornando assim o diagnóstico da doença mais fácil na vida adulta, deste modo à existência da hanseníase em menores de 15 anos indica uma exposição precoce da criança ou adolescente ao M. leprae, revelando desta forma hiperendemicidade da hanseníase na região analisada (MONTALVÃO et al., 2018).

\begin{abstract}
RESUMO
Objetivo: determinar a tendência da hanseníase em menores de 15 anos de acordo com os casos novos da doença por região do Brasil no recorte temporal de 2007 a 2017. Materiais e Métodos: a pesquisa tratou-se de uma análise descritiva, transversal e quantitativa dos casos registrados no Sistema de Informação de Agravo e Notificação, onde toda a análise foi desenvolvida com nível de significância de 5\%. Resultados: a tendência da hanseníase nas cinco regiões brasileiras apresentou-se decrescente e a APC geral foi igual a $-0,007$ (IC95\% - 0,$009 ;-0,005$ ), a região Norte foi a que apresentou maiores índices sobre a taxa de detecção da doença e o Sul a que revelou valores mais baixos. Conclusão: embora a hanseníase vem-se regredido ao decorrer dos anos a própria ainda continua sendo um grande problema de saúde pública, uma vez que sua taxa de detecção apresenta-se hiperendêmica em algumas regiões.
\end{abstract}

Palavras-chave: Hanseníase. Notificação de Doenças. Epidemiologia.

\section{ABSTRACT}

Objective: to determine the tendency of leprosy in children under 15 years old according to new cases of the disease by region of Brazil in the time frame from 2007 to 2017. Materials and Methods: the research was a descriptive, transversal and quantitative analysis of the cases registered in the Disclosure and Notification Information System, where the entire analysis was carried out with a significance level of $5 \%$. Results: the trend of leprosy in the five Brazilian regions was decreasing and the general APC was equal to 0.007 (95\% CI $-0.009 ;-0.005)$, the North region had the highest rates of detection of the disease and the South showed the lowest values. Conclusion: although leprosy has regressed over the years, it still remains a major public health problem, since its detection rate is hyper-endemic in some regions.

Keywords: Leprosy. Disease Notification. Epidemiology.

Submetido em: 08 de nov. 2019

Aceito em: 14 de fev. 2020

${ }^{1}$ Centro Universitário FG - UNIFG, Guanambi, Bahia - Brasil

"E-mail para correspondência: kellearaujogbi@ hotmail.com 
Sendo considerada um grave problema de Saúde Pública, a hanseníase apenas no ano de 2016 apresentou 214.783 casos novos da doença a nível mundial, onde 25.218 foram correspondentes ao Brasil, sendo o mesmo o país que ocupou a segunda colocação no ranking dos que obtiveram maiores taxas em relação ao número de casos novos da doença no ano 2016. A Índia foi o único país que superou os registros do Brasil, e a República democrática do Congo, Nepal e Bangladesh foram os que ocuparam a terceira, quarta e quinta posição respectivamente (WHO, 2017).

Assim, a realização de pesquisas e divulgação dos resultados de estudos sobre a hanseníase nas regiões brasileiras fundamenta-se na importância do conhecimento da atual situação da doença nessas regiões e no incentivo às instituições governamentais a atuarem no controle da doença ou até mesmo a sua erradicação. Neste contexto, o presente estudo objetivouse em determinar a tendência da hanseníase em menores de 15 anos de acordo com os casos novos da doença por região do Brasil no recorte temporal de 2007 a 2017.

\section{MATERIAIS E MÉTODOS}

$\mathrm{O}$ estudo tratou-se de uma pesquisa transversal, quantitativa e descritiva dos casos novos de hanseníase em menores de 15 anos nas regiões brasileiras no recorte temporal de 2007 a 2017.

Os dados foram coletados através dos registros disponíveis no banco de dados do SINAN (Sistema de Informação de Agravo e Notificação), vinculado ao DATASUS (Departamento de Informática do Sistema Único de Saúde). Foram considerados para a análise todos os casos novos que possuíam data de notificação no período de tempo estipulado e eliminado os que não eram casos novos e não estavam dentro do recorte temporal predestinado.

Quanto à tabulação dos dados, a mesma deu-se por meio do programa Microsoft Excel® 2010, onde também foram gerados os gráficos, para a análise das tendências utilizou-se o software BioEstat 5.3, no qual foi empregado a fórmula $\mathrm{Y}=\mathrm{b} 0+\mathrm{b} 1 \mathrm{x}$, onde $\mathrm{b} 0$ refere-se a convergência da reta e o eixo vertical e b1 a inclinação da reta. Foi aplicado ainda a conversão logarítmica dos valores de $\mathrm{Y}$ com o intuito de diminuição da heterogeneidade da variância dos resíduos. $\mathrm{O}$ valor de $\mathrm{X}$ foi dado de acordo ao ano de cada análise e todo o estudo foi desenvolvido com nível de significância de 5\% (ANTUNES; CARDOSO, 2015).

Para classificação da tendência das regiões em crescente, decrescente ou estacionária foi adotado o método da tendência ou mudança percentual (annual percent change) APC, tendo como fórmula APC $=[-1+10 \mathrm{~b} 1]$ $* 100 \%$ e $95 \%$ (IC95\%=[-1+10b1mín.] *100\%; [-1+10b1máx.] *100\%). A classificação foi dada de acordo com o resultado de APC, no qual caso o valor encontrado fosse negativo a tendência classificaria-se como decrescente e quando positivo crescente (ANTUNES; CARDOSO, 2015).

Sobre o cálculo da taxa de detecção o próprio teve como numerador o número de casos novos de hanseníase em menores de quinze anos na região estudada dividido pela sua população total multiplicado por 100.000 . O cálculo foi realizado través da média do número de casos novos e a média da população total no período de tempo condizente a análise (BRASIL, 2010).
Por se tratar de um estudo realizado por meio de dados secundários o mesmo torna-se isento de avaliação do comitê de ética, entretanto toda a pesquisa foi desenvolvida de acordo com os cuidados estabelecidos na resolução de $n^{\circ}$ 466/2012 do Conselho Nacional de Saúde (BRASIL, 2016).

\section{RESULTADOS}

As tendências nas cinco regiões brasileiras apresentaram-se decrescentes, sendo APC igual a -0,021 (IC 95\% $-0,029 ;-0,014)$ para a região Norte; 0,017 (IC $95 \%-0,023 ;-0,012$ ) para o Nordeste; -0,032 (IC 95\% -0,038; 0,027 ) para o Sudeste; $-0,34$ (IC 95\% 0,503 ; -0174) para o Sul e $-0,026$ (IC $95 \%-0,080 ; 0,027)$ para o CentroOeste, assim como todas as regiões brasileiras o Brasil em geral também apresentou tendência positiva (Figura $1)$.

Figura 01 - Tendência da Hanseníase em relação aos casos novos da doença em menores de 15 anos no Brasil entre 2007 e 2017. APC $=-0,007$ (IC95\% $-0,009 ;-0,005)$.

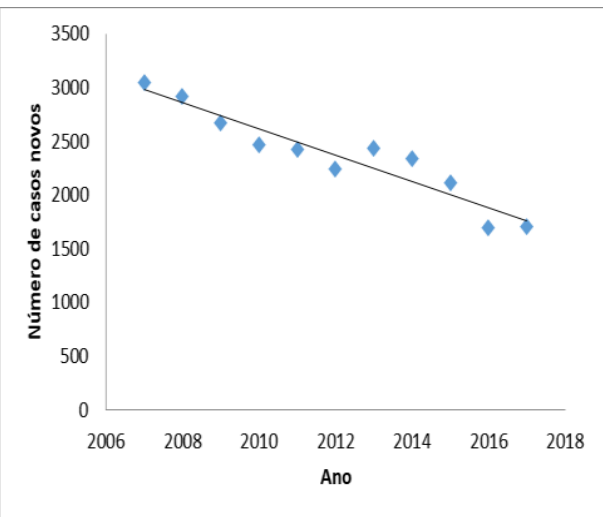

Fonte: SINAN

A região que apresentou maior destaque sobre a taxa de detecção da hanseníase em menores de 15 anos foi à região Norte, apresentando 12,28 casos por 100.000 habitantes, seguido do Centro-Oeste com 8,14; Nordeste com 7,58; Sudeste com 1,41 e sul com 0,32 (Figura 2). 
Figura 02 - Taxa de detecção da Hanseníase em menores de 15 anos por região do Brasil entre 2007 e 2017.

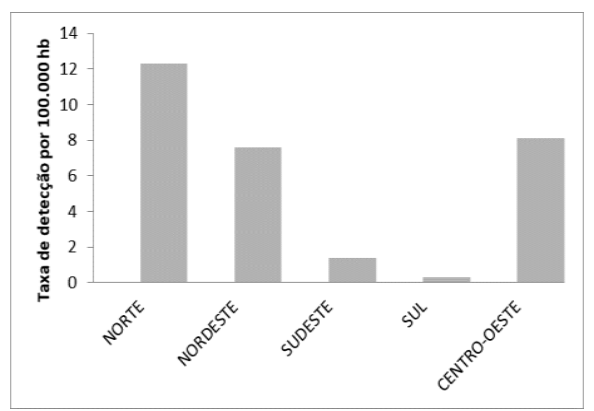

Fonte: SINAN

\section{DISCUSSÃO}

Embora a hanseníase em menores de 15 anos no recorte temporal estudado apresenta resultados favoráveis à taxa de diminuição da doença, a mesma ainda continua sendo um grave problema de saúde pública, pois a taxa de detecção da própria revela-se divergente entre as regiões brasileiras, enfatizando em algumas dessas a situação de hiperendemicidade $(\geq 10,0$ casos por 100.000 habitantes) (SCHNEIDER, FREITAS, 2018).

Assim como a presente pesquisa, outras análises realizadas em países diferentes também revelam o mesmo resultado, como por exemplo, a Arábia Saudita e a Coréia (ASSIRI et al., 2014; LEE et al., 2015). Essa diminuição se dá possivelmente devido a população está possuindo um maior acesso no que se refere aos serviços de saúde, além do oferecimento da poliquimioterapia (PQT) aos indivíduos que são detectados com a doença (FREITAS; CORTELA; FERREIRA, 2017).

Ainda se tratando dessa circunstância, a busca por contatos é um dos fatores que também contribui para a diminuição da Hanseníase, uma vez que este processo visa detectar a fonte de contágio da doença implementando medidas de prevenção sobre a situação (SCHNEIDER, FREITAS, 2018).

Segundo Ribeiro, Silva e Oliveira (2018), um dos fatores que contribui para a diferença entre a situação epidemiológica das doenças infectocontagiosas no Brasil são as condições socioeconômicas de cada região, sendo o Norte, Nordeste e Centro-Oeste as regiões menos favoráveis no que tange os critérios econômicos do país. O Sul por sua vez encontra-se com maior nível de desenvolvimento, coincidindo assim com a sua baixa taxa de detecção.

Outro fator que implica no destaque da região Norte sobre a taxa de detecção da hanseníase são os ocorridos na década de 1970, no qual houve uma ênfase na construção de rodovias federais com o intuito de expansão agrícola, expansão essa que segundo Schneider e Freitas (2018) favoreceu a agregação de vários municípios, tornando assim a doença endêmica nessa região, isso devido uma maior circulação do M. leprae. Resultado semelhante a este também é observado em outro estudo realizado no Brasil no período de 2001 a 2016 (SCHNEIDER, FREITAS, 2018).

\section{CONCLUSÃO}

A hanseníase em menores de 15 anos vem apresentando regressão sobre os números de casos novos da doença no Brasil, entretanto a mesma ainda continua sendo considerada um grande problema de saúde pública, uma vez que sua taxa de detecção apresenta-se hiperendêmica em algumas regiões. Evidencia-se também um destaque sobre a região Norte do país, onde de acordo com a literatura as condições socioeconômicas e históricas do Brasil favoreceram a tal situação.
Para que a Hanseníase possa chegar ao seu controle total ou até mesmo a sua eliminação, necessita-se ainda a realização de estudos mais aprofundados acerca do tema, pois quanto mais explorada são as suas variáveis epidemiológicas, mais fácil se torna o direcionamento governamental e/ou de outras entidades no controle da doença.

\section{REFERÊNCIAS}

ANTUNES, J. L. F.; CARDOSO, M. R. A. Uso da análise de séries temporais em estudos epidemiológicos. Epidemiologia e Serviços de Saúde,

[s.l.], v. 24, n. 3, p. 565-576, set. 2015.

ASSIRI, A.; YEZLI, S.; TAYEB, T.; ALMASRI, M.; BAMGBOYE, A. E.; MEMISH, Z. A. Eradicating leprosy in Saudi Arabia: outcome of a tem-year surveillance (2003-2012). Travel Med Infect Dis, v. 12, n. 6, p.771-7, 2014.

BRASIL. Ministério da Saúde. Gabinete do Ministro. Aprova as Diretrizes para Vigilância, Atenção e Controle da hanseníase. Portaria $\mathrm{N}^{\mathrm{o}} 3.125$, de 7 de outubro de 2010. Brasília - DF, 2010. Disponível em:

http://bvsms.saude.gov.br/bvs/saudele gis/gm/2010/prt3125_07_10_2010.htm 1. Acesso em: 21 Maio. 2019.

FREITAS, B. H. B. M.; CORTELA, D. C. B.; FERREIRA, Silvana Margarida Benevides. Trend of leprosy in individuals under the age of 15 in Mato Grosso (Brazil), 2001-2013. Revista de Saúde Pública, [s.1.], v. 51, p. 110, 2017.

LEE, J.; KIM, J. P.; NISHIKIORI, N.; FINE, P. E. The decline of leprosy in the Republic of Korea: patterns and trends 1977-2013. Lepr Ver, v. 86, n. 4, p. 316-27, 2015.

MARQUES, L. E. C. et al. Evaluation of 16S rRNA qPCR for detection of Mycobacterium leprae DNA in nasal secretion and skin biopsy samples from multibacillary and paucibacillary 
leprosy cases. Pathogens And Global

Health, [s.1.], v. 112, n. 2, p. 72-78, 26 dez. 2017.

MONTALVÃO, L. M. et al. Diagnosis and treatment of hanseniasis: physiotherapist activation. Revista FAIPE, [s.l.], v. 8, n. 1, p. 72-84, 2018.

RIBEIRO, M. D.; SILVA, J. C.; OLIVEIRA, S. Estudo epidemiológico da hanseníase no Brasil: reflexão sobre as metas de eliminação. Revista Panamericana de Salud Pública, [s.l.], p. 1-7, 2018.

SCHNEIDER, P. B.; FREITAS, B. H. B. M. Tendência da hanseníase em menores de 15 anos no Brasil, 20012016. Cadernos de Saúde Pública, [s.1.], v. 34, n. 3, p.1-11, 12 mar. 2018.

WHO - World Health Organization. Weekly epidemiological record. Global leprosy update, 2016: accelerating reduction of disease burde, n. 35, 501519p, 2017. 